\title{
Potential Mechanism of Action of Cyclosporin A in Human Dermal Fibroblasts-Transcriptomic Analysis of CYPs
}

\author{
Grażyna Janikowska ${ }^{1, *}$, Alina Pyka-Pająk ${ }^{1}$, Tomasz Janikowski ${ }^{2}$, Jolanta Adamska ${ }^{2}$, \\ Urszula Mazurek ${ }^{2}$ and Przemysław Jędrusik ${ }^{2,3}$ \\ 1 Department of Analytical Chemistry, Medical University of Silesia, Jagiellońska 4, 41-200 Sosnowiec, Poland; \\ apyka@sum.edu.pl \\ 2 Department of Molecular Biology, Medical University of Silesia, Jedności 8, 41-200 Sosnowiec, Poland; \\ tomekjanikowski@wp.pl (T.J.); jolaa@sum.edu.pl (J.A.); umazurek@sum.edu.pl (U.M.); \\ pjedrusik@sum.edu.pl (P.J.) \\ 3 Department of Biomedical Computer Systems, University of Silesia, Będzińska 39, 41-205 Sosnowiec, Poland \\ * Correspondence: gjanikowska@sum.edu.pl; Tel.: +48-32-364-1560
}

Received: 28 May 2018; Accepted: 2 July 2018; Published: 5 July 2018

check for updates

\begin{abstract}
Effect of cyclosporin A (CsA) in a therapeutic concentration, on the expression of cytochrome $\mathrm{P} 450$ genes (CYPs), was investigated in normal human dermal fibroblast cells. The expression of 57 genes, encoding cytochrome P450 isoforms, was estimated using the microarray method. Amongst 396 normalized fluorescence signals related to cytochrome P450 activity, only 91 were strictly connected to $C Y P s$ and were analyzed using two methods: a self-organizing feature map of artificial neural networks and typical statistical analysis with significance level at $p \leq 0.05$. Comparing the samples from fibroblasts cultured with CsA and those cultured without, up-regulated changes of CYP19A1, 1B1, 7A1, 7F1, 17A1 and down-regulated 2D6 gene expression were observed. The mRNAs with increased changes were in the same neuron of the self-organizing feature map. All distinguished CYPs encode monooxygenases, which plays an important role in steroids biosynthesis and metabolism. Based on the obtained results, we can conclude that CsA in therapeutic concentration changes the expression profile of CYPs in human dermal fibroblasts, especially affecting genes linked to steroids synthesis and/or metabolism. It shows the potential mechanism of action of CsA in human dermal fibroblast cells.
\end{abstract}

Keywords: cyclosporin A; cytochrome P450 gene; fibroblasts; microarray; MTT test; SOFM

\section{Introduction}

Cyclosporin A (CsA) is a classic immunosuppressive drug used, not only to prevent organ or tissue rejection, but also in many immunologically-mediated diseases, for example, atopic dermatitis, pyoderma gangrenosum, pemphigus, psoriasis, rheumatoid arthritis and dry eye [1-3]. There are good effects in patient treatment in the aforementioned diseases even in oral doses [4]. CsA is metabolized by cytochrome P450 (CYP), mainly by the isoform CYP3A4; it also works as an inhibitor of $3 A 4,2 C 19$ and 2D6 in human liver microsomes [5].

Cytochrome P450 is a large, multifunctional superfamily of 57 genes encoding monooxygenases, which catalyze the conversion of many endobiotics and xenobiotics and have a strong clinical significance [6]. It also produces chemicals essential for homeostasis, as well as bile acids, cholesterol, steroids, lipids, vitamin D, retinoids, and biogenic amines. CYPs are involved in the metabolism of most drugs, chemicals and environmental pollutants, as well as endogenous substances [6,7]. The expression 
of CYP is tissue and organ selective [8]. Expression of different CYPs has been stated in cultured keratinocytes, Langerhans cells, fibroblasts and melanocytes [9].

CYP's activity can be induced or inhibited by multiple endogenous and exogenous compounds [10]. Changes in expression of CYP genes in various skin models and cells were observed under influence of many different xenobiotics [11]. Human dermal cells are capable of metabolizing CsA [12]. Little is known about the effects of CsA on the cytochrome P450 family in human dermal fibroblasts. After oral administration, CsA reduces symptoms of psoriasis; however, it also plays a predominant role in the pathophysiology of nonmelanoma skin cancer in kidney transplant recipients [13]. Human skin fibroblasts are vital machinery for local production, conversion, metabolism and/or inactivation of many endogenic substances such as neurotransmitters, neuropeptides and typical hormones; cytochrome P450 is a key enzyme in these reactions [14,15]. This makes dermal fibroblasts a relevant model to investigate these genes under the influence of therapeutic CsA concentration. To enable a wide and accurate view of the cytochrome P450 family gene expression in human dermal fibroblasts, a microarray was used as a method of choice. A neural network of self-organizing feature maps was used to analyze the results, and these were confirmed by classical methods. The use of this allowed to select only the CYPs, which are activated by CsA in the dermal fibroblasts.

Thus, the aim of this study was to estimate the effect of CsA on the CYP's expression in normal human dermal fibroblast cells.

\section{Results}

The examined amounts of CsA (in the tested range of concentrations) had not shown a toxic effect on fibroblasts in MTT (Microculture Tetrazolium Test) test and results are presented in Figure 1.

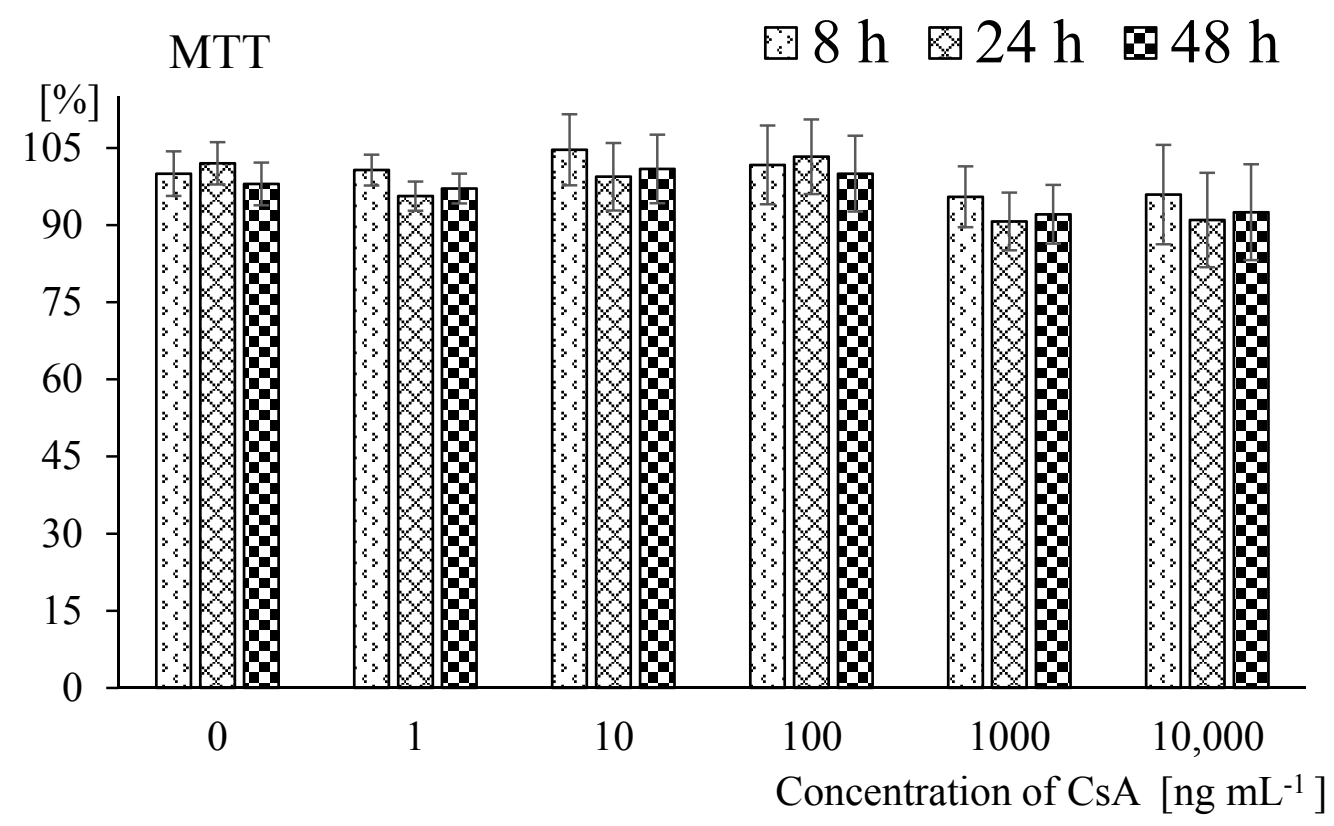

Figure 1. Cell viability after exposure to cyclosporin A (CsA). Legend: Exposure to different concentration of CsA for 8, 24 and $48 \mathrm{~h}$ in dermal fibroblasts estimated by the MTT assay (the results are showed as percent of the absorbance in control samples, mean $\pm \mathrm{SD}$; and lack of significance, $>0.05$ ).

Based on these results, a concentration of $100 \mathrm{ng}$ per $1 \mathrm{~mL}$ of medium was used for future analysis, which was both comparable to the standard therapeutic dose in patients' blood as well as nontoxic.

The obtained gene expression results were used to perform two analyses. The first approach was by creating clusterization with a Kohonen map (SOFM) [16], and the second by classical statistical 
analysis. The next step was to filter the set of entities for statistical significance with ANOVA, and then evaluate the distribution of 101 (35 CYPs) from 396 mRNA (Table S1) fluorescence signals by creating a hierarchical clusterization with Euclidean distances, using the Ward method. For this purpose, Euclidean distances were calculated by taking two main clusters from which the left one was divided into two sub-groups. In turn, the right one was split into four sub-clusters (Figure 2). To verify the grouping and to choose the optimal neural network, the Davies-Bouldin value [17] (with mixed Gaussian distribution) was calculated. For this artificial neural network, the optimal $\mathrm{k}$ was for 3 neurons, with a critical value of 0.9134 . The distribution graph of SOFM for the selected neurons is presented in Figure 2.

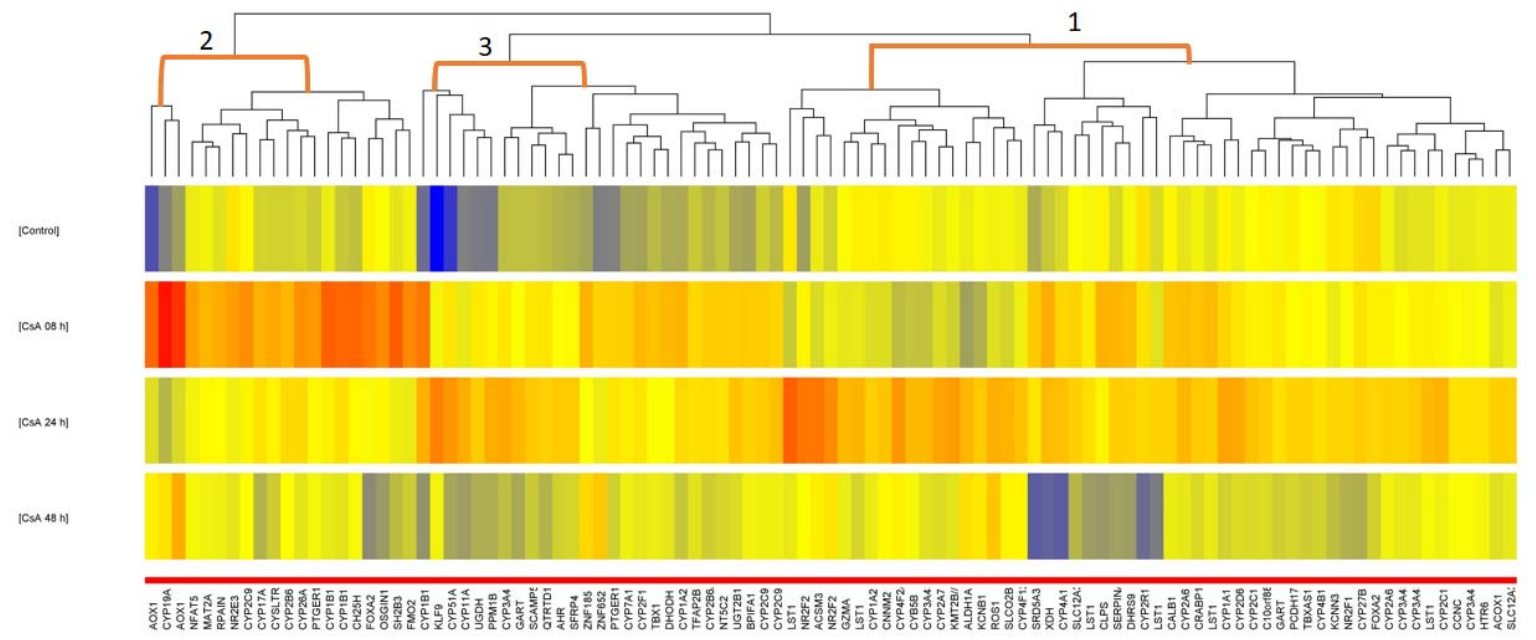

Figure 2. Distribution of 101 (from 396) significant transcripts linked to cytochrome P450 activity in human dermal fibroblast cells in different time of exposure to CsA. Legend: Self-organizing feature map visualized in vertical cluster tree-entities, and in horizontal conditions (three samples per each condition ( 0 control; $8,24,48 \mathrm{~h} \mathrm{CsA}$ ); heat maps show the color range of differences in classification of normalized fluorescence signals. The values are visualized from red (high) to blue (low).

The inductive activities of CsA in the investigated fibroblasts showed in the following distinguished transcripts: CYP19A1 (aromatase), CYP1B1 (monooxygenase), CYP2F1 (monooxygenase), CYP7A1 (cholesterol 7 $\alpha$-hydroxylase) and CYP17A1 (17 $\alpha$-hydroxylase) (criteria: $p<0.05$ and FC $>1.2$ for CsA 8 h vs. 0; Table 1).

Table 1. Cytochrome P450 (CYPs) differentiating NHDFs (normal human dermal fibroblast) exposed on CsA in various time of culture.

\begin{tabular}{|c|c|c|c|c|c|c|}
\hline \multirow{2}{*}{$\begin{array}{l}\text { Gene } \\
\text { Symbol }\end{array}$} & \multicolumn{3}{|c|}{ Fold Change } & \multirow{2}{*}{$p$ Value } & \multirow{2}{*}{$\begin{array}{l}\text { SOFM } \\
\text { Neuron }\end{array}$} & \multirow{2}{*}{ Biological Process } \\
\hline & $8 \mathrm{~h}$ vs. 0 & $24 \mathrm{~h}$ vs. 0 & $48 \mathrm{~h}$ vs. 0 & & & \\
\hline CYP19A1 & 1.72 & 1.07 & 1.24 & 0.0006 & 2 & $\begin{array}{l}\text { steroids biosynthesis and } \\
\text { metabolism }\end{array}$ \\
\hline CYP1B1 & 1.52 & 1.39 & 1.05 & 0.0030 & 2,3 & steroids metabolism \\
\hline CYP2F1 & 1.26 & 1.18 & 1.09 & 0.0050 & 2 & $\begin{array}{l}\text { metabolism and synthesis of } \\
\text { lipids, cholesterol, steroids }\end{array}$ \\
\hline CYP7A1 & 1.22 & 1.16 & 1.16 & 0.0330 & 2 & steroids biosynthesis \\
\hline CYP17A1 & 1.20 & 1.11 & -1.04 & 0.0500 & 2 & $\begin{array}{l}\text { biosynthesis of cholesterol, } \\
\text { lipids, steroids }\end{array}$ \\
\hline
\end{tabular}


The neural networks showed a resemblance between CYP19A1, 2F1, 7A1 and 17A1, which took place in the same neuron 2, as well as $1 B 1$ (four different probes) in both (see Table 1). The 101 mRNA from ANOVA related to CYPS was also analyzed using the post hoc Tukey's test in all four study groups $(0,8,24,48 \mathrm{~h})$. The analysis gave many statistically significant mRNAs for CsA: 41 for $8 \mathrm{~h}$ vs. $0 ; 26$ for $24 \mathrm{~h}$ vs. $0 ; 34$ for $48 \mathrm{~h}$ vs. 0 (Figure 3,p $\leq 0.05$ ). The CYPs that are mentioned in Table 1 were among 18 characteristics for $8 \mathrm{~h}$ vs. 0 samples.

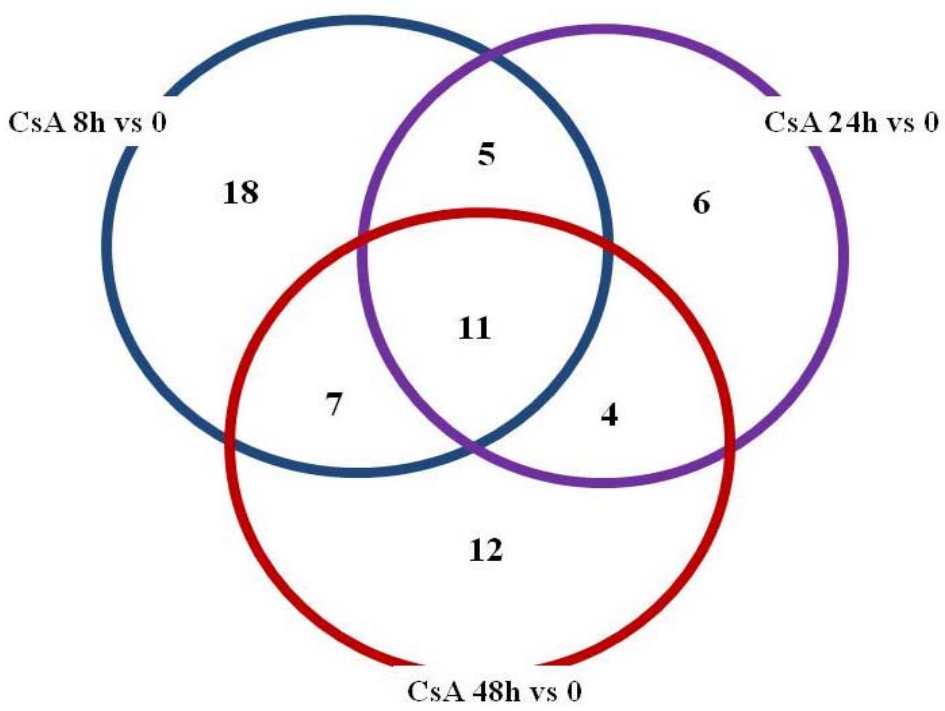

Figure 3. Venn diagram based on 101 transcripts selected as significant $(p \leq 0.05)$ in Tukey's post hoc test from 396 linked to cytochrome P450 mRNAs at different time of exposure to CsA.

When comparing the fluorescence signals for 91 mRNAs of cytochrome P450 (Table S2) in the NHDF cultures with and without CsA, it was demonstrated that $31 \mathrm{mRNA}$ of CYPs were up-regulated, 15 were down-regulated, and only twelve had significant changes $(\leq 0.05$, Table 2$)$ in $8 \mathrm{~h}$ of exposure compared to the control.

Those from Table 1 were found with the following up-regulated mRNA encoding monooxygenases: $1 A 2,2 C 19$ as well as $51 A 1$ (encode sterol 14- $\alpha$ demethylase) from neuron 3 , which are represented only by one out of two or three probes, respectively.

The analyses lead to distinguishing genes, which expression can influence the metabolism of CsA in normal human dermal fibroblasts. Additionally, Table 2 is showing 47 CYPs mRNA; their presence in human dermal fibroblast cells was already stated.

Taking into consideration all the methods used, the FC and value, and the expression of all probes, the six CYPS (19A1, 1B1, 2F1, 7A1, 17A1 and 2D6) were distinguished. In summary, the genes have biological significance, and directly or indirectly, are connected to biosynthesis, and/or the metabolism of steroids. 
Table 2. Transcripts present in human dermal fibroblasts and comparison of culture with and without CsA in the $\mathrm{T}$ test and the Self-Organizing Feature Map (SOFM).

\begin{tabular}{|c|c|c|c|c|c|c|}
\hline No. & Probe ID & Transcript & $\begin{array}{l}\text { NHDFs Control (0) } \\
\text { Mean }\left[\log _{2} \text { FS] }\right.\end{array}$ & $\begin{array}{l}\text { NHDFs with CsA (8 h) } \\
\text { Mean }\left[\log _{2} \mathrm{FS}\right]\end{array}$ & $t$ Test & $\begin{array}{l}\text { SOFM } \\
\text { Neuron }\end{array}$ \\
\hline 1 & 202436_s_at & $1 B 1$ & 12.24 & 12.64 & $\uparrow$ & 2 \\
\hline 2 & 208131_s_at & $8 A 1$ & 12.15 & 12.27 & NS & \\
\hline 3 & 202435_s_at & $1 B 1$ & 11.32 & 11.77 & $\uparrow$ & 2 \\
\hline 4 & 202437_s_at & $1 B 1$ & 10.78 & 11.38 & $\uparrow$ & 3 \\
\hline 5 & 216661_x_at & $2 C 19 / 9$ & 8.62 & 8.62 & NS & \\
\hline 6 & 209975_at & 2.E1 & 8.46 & 8.46 & NS & \\
\hline 7 & 202314_at & $51 A 1$ & 8.39 & 8.85 & $\uparrow$ & 3 \\
\hline 8 & 210726_at & $3 A 4$ & 7.96 & 8.03 & NS & \\
\hline 9 & 219825_at & $26 B 1$ & 7.83 & 7.71 & NS & \\
\hline 10 & 214234_s_at & $3 A 5$ & 7.81 & 7.90 & NS & \\
\hline 11 & 216025_x_at & $2 C 19 / 9$ & 7.75 & 7.60 & NS & \\
\hline 12 & 209148_at & $2 C 8$ & 7.58 & 7.71 & NS & \\
\hline 13 & 203979_at & $27 A 1$ & 7.49 & 7.62 & NS & \\
\hline 14 & 219565_at & $20 A 1$ & 7.47 & 7.49 & NS & \\
\hline 15 & 205998_x_at & $3 A 4$ & 6.42 & 6.59 & NS & \\
\hline 16 & 207244_x_at & $2 A 6$ & 6.32 & 6.32 & NS & \\
\hline 17 & 203475_at & $19 A 1$ & 6.25 & 7.04 & $\uparrow$ & 2 \\
\hline 18 & 220432_s_at & $39 A 1$ & 5.47 & 5.52 & NS & \\
\hline 19 & 215103_at & $2 C 18$ & 5.47 & 5.34 & NS & \\
\hline 20 & 214630_at & $11 B 2$ & 5.25 & 5.34 & NS & \\
\hline 21 & 215982_s_at & $21 A 2$ & 5.23 & 5.33 & NS & \\
\hline 22 & 214419_s_at & $2 C 9$ & 5.16 & 5.10 & NS & \\
\hline 23 & 202434_s_at & $1 B 1$ & 5.16 & 5.50 & $\uparrow$ & 2 \\
\hline 24 & 209976_s_at & 2.E1 & 4.94 & 4.75 & NS & \\
\hline 25 & 207498_s_at & $2 D 6$ & 4.69 & 4.45 & $\downarrow$ & 1 \\
\hline 26 & 216607_s_at & $51 A 1$ & 4.63 & 4.56 & NS & \\
\hline 27 & $1494 \_f$ at & $2 A 6$ & 4.63 & 4.69 & NS & \\
\hline 28 & 220562_at & $2 W 1$ & 4.62 & 4.54 & NS & \\
\hline 29 & 211231_x_at & $4 A 11$ & 4.55 & 4.74 & NS & \\
\hline 30 & 207386_at & $7 B 1$ & 4.51 & 4.69 & NS & \\
\hline 31 & 205765_at & $3 A 5$ & 4.49 & 4.34 & NS & \\
\hline 32 & 208327_at & $2 A 13$ & 4.49 & 4.61 & NS & \\
\hline 33 & 211440_x_at & $3 A 43$ & 4.46 & 4.65 & NS & \\
\hline 34 & 210576_at & $4 F 8$ & 4.35 & 4.29 & NS & \\
\hline 35 & 211295_x_at & $2 A 6$ & 4.33 & 4.49 & NS & \\
\hline 36 & 220331_at & $46 A 1$ & 4.32 & 4.44 & NS & \\
\hline 37 & 210452_x_at & $4 F 2$ & 4.24 & 4.17 & NS & \\
\hline 38 & 207609_s_at & $1 A 2$ & 4.20 & 4.10 & NS & \\
\hline 39 & 206539_s_at & $4 F 12$ & 4.18 & 4.21 & NS & \\
\hline 40 & 214320_x_at & $2 A 6$ & 4.17 & 3.88 & NS & \\
\hline 41 & 204309_at & $11 A 1$ & 4.16 & 4.39 & NS & \\
\hline 42 & 207608_x_at & $1 A 2$ & 4.14 & 4.44 & $\uparrow$ & 3 \\
\hline 43 & 205502_at & $17 A 1$ & 4.06 & 4.33 & $\uparrow$ & 2 \\
\hline 44 & 1431_at & 2.E1 & 4.01 & 3.67 & NS & \\
\hline 45 & 216058_s_at & $2 C 19$ & 3.17 & 3.40 & $\uparrow$ & 3 \\
\hline 46 & 207406_at & $7 A 1$ & 2.49 & 2.79 & $\uparrow$ & 2 \\
\hline 47 & 207913_at & $2 F 1$ & 2.51 & 2.86 & $\uparrow$ & 2 \\
\hline
\end{tabular}

Abbreviations are as follows: Normal human dermal fibroblast (NHDF); hour (h); fluorescence signal (FS); no significance (NS).

\section{Discussion}

The MTT test did not show any toxic effects of CsA in the examined concentrations on NHDFs. The result should be considered as a positive because the selection of concentration for the experiment was based on previous clinical experience. Hence, for the microarray experiment. the chosen amount was a therapeutic concentration of CsA $\left(100 \mathrm{ng} \mathrm{mL}^{-1}\right)$, which occurs in the circulating blood of treated patients [18-20]. Other findings confirm that CsA concentrations lower than $300 \mathrm{ng}$ in $1 \mathrm{~mL}$ of medium 
are safe, not genotoxic nor mutagenic in normal human fibroblast cells (MRC-5) and did not affect investigated cell viability and proliferation [21]. Our findings provide a preliminary in vitro study that CsA does not have a significant influence on viability of fibroblast cells in 1-10,000 ng per mL range; however in therapeutic concentrations it changes the expression of $C Y P$ genes.

The microarray analysis provides a large-scale look inside the analyzed cells, giving a unique chance to understand the changes in response to CsA; our results are based on 396 transcripts in four cultures with and without CsA. Although gene expression does not fully show the amount of the gene product, it provides an insight into cell metabolism and indicates ongoing changes.

A number of studies which have used cell cultures, tried to explain the action and cause of side effects of CsA: among others, excessive proliferation, diabetes, hypertension, and the increased risk of non-melanoma skin cancers, especially squamous cell carcinoma [21-24]. A previous study proved that steroidogenesis and CYPS are involved in the pathology of skin cancer [15]. Our experiment used advanced statistical analysis, enabling a classification of main CYPs that may be involved in the process of dermal fibroblasts activation. The results were analyzed with the use of neural networks and a standard statistic method to calculate the impact of CsA on gene expression. The use of an artificial neural network has a wide range of usage in drug research, enabling the prediction of various processes [25]. In microarray analysis, the large amount of results can be used to create Kohonen self-organizing maps, which give the opportunity to cluster the analyzed gene expression data, showing possible interaction between them based on a mathematical algorithm [26]. The implemented clusterization illustrated a relationship between them and also highlighted the influence of CsA on the NHDF metabolism. The SOFM showed a trend in the results and indicated the resemblance in CYP's expression under the influence of CsA. When looking at the distribution of the listed genes in the SOFM analysis and comparing it to their function and expression under the influence of CsA, a pattern can be seen. The created SOFM groups are a visualization of the interaction of NHDFs with CsA. It is visible that neuron 2 has higher fold change values in the first $8 \mathrm{~h}$ (Table 1), after which point it returns to a rather normal state. Probably these genes' products have more specific roles and are not needed at first. As for neuron 3, the fold change of transcripts has a high level of deregulation in the first $8 \mathrm{~h}$, after which they remain at an up or down regulated level (what we can see in color differences in Figure 2). It seems that the induced or inhibited genes could be strictly linked to a response to the added drug. Such data correlated with the ANOVA results not only allowed the grouping of significant genes, but also connected their expression to the effect of the drug. The distinguished genes which were different in the first $8 \mathrm{~h}$ of culture were assigned to adjacent neurons 2 or 3 of the Self-Organizing Feature Map (SOFM) (Figure 2; Tables 1 and 2) and included CYPS: 19A1, 1B1, 2F1, 7A1 and 17A1.

CYP19A1 gene product in the cell acts as an aromatase (also known as estrogen synthase or estrogen synthetase), a key enzyme in estrogen synthesis, which is responsible for aromatization of androgens (i.e., testosterone) into estrogens (i.e., estradiol) [27]. Similar to our findings, the presence of 19A1 was found in the fibroblast cells [28]. Additionally, authors proved that its expression was correlated with the estrogen level in the skin.

CYP1B1 encodes ubiquitous hydroxylase, which catalyzes the hydroxylation reaction of many xenobiotics and endobiotics: these can be things such as drugs, environmental pollutants, lipids, cholesterol, and/or steroid hormones (a key enzyme in androgen metabolism to estrogen and testosterone) [6]. This gene is expressed in normal keratinocytes, melanocytes and fibroblasts as well as in induced skin cells $[9,11,29]$. Its expression and activity is connected to hormones that can induce some forms of cancer [27]. Our findings show the presence of $1 B 1$ in the human dermal fibroblasts, up-regulated in response to CsA.

The CYP2F1 gene is little known and encodes monooxygenase, which takes part in steroidogenesis.

CYP7A1 encodes cholesterol $7 \alpha$-hydroxylase, which is a crucial enzyme in the synthesis and homeostasis of cholesterol [30,31]. Products of this gene (7-hydroxylases) potentially can 
produce 7-hydroxy/oxy-steroids/sterols with modifying effects on local homeostasis in the skin [14]. Our results (Tables 1 and 2) showed that CYP7A1 is significantly increased in response to CsA.

CYP17A1 mainly acts as gene coding pregnenolone and progesterone $17 \alpha$ hydroxylase and also as monooxygenase takes part in other reactions of steroidogenesis as a key enzyme, and also in drugs metabolism [6]. Its presence was found in keratinocytes and fibroblasts [30], similar to our results. Furthermore, we found that CsA stimulates its expression in human dermal fibroblasts (Tables 1 and 2).

Genes in the third neuron of SOFM, belonging to different cytochrome P450 families such as $1 A 2$, 2C19 and 51A1, were up-regulated (Tables 1 and 2).

CYP1A2 plays a major role in the synthesis of cholesterol, steroids and lipids in the liver [6]. Low levels or amounts below the level of detection of $1 A 2$ were found in the skin [32]. Similar to our findings, where CsA induced the 1A2, it was shown that coal tar increased expression of this gene in the skin [33]. CYP2C19 is involved in xenobiotic metabolism (including medicines) and synthesis of cholesterol, steroids and lipids [6]. Previously, its presence was found in fibroblasts [30], similar to our findings. Additionally, our results showed an increase in expression of this gene in skin fibroblasts in response to CsA. CYP51A1 catalyzes one of the earliest stages of cholesterol biosynthesis, namely the C14-demethylation of lanosterol [34]. Our findings show that CsA in therapeutic concentration can possibly induce its expression in the fibroblast cells. As indicated in the results, these transcripts are represented only by one probe out of two or three on microarray. Thus, the mentioned results are uncertain. CYPs are tissue-specific genes and their expression may differ.

Primarily connected with drug metabolism, in our results, CYP2D6 belongs to neuron 1 and is down-regulated. Similar to our findings (a decrease in response to CsA), it was shown to reduce expression of CYP2D6 in EpiDerm ${ }^{\mathrm{TM}}$ tissues relative to full thickness human buttock skin [35]. Its expression was found in different skin cells $[9,32,36,37]$. The presence of all the aforementioned genes in human dermal fibroblasts has been found even in those with the weakest expression (Table 2).

In summary, the microarray analysis gives a good inside view of the cells and their reaction to the drug. Implementing an artificial neural network by clustering gene expression signals in the analyzed groups, and ANOVA with a post hoc test, shows that the same statistically significant genes characterize the processes in the cell in response to a stress factor like a drug being added. The fold change 1.2-1.7 for $C Y P$ genes may not be high but still show significant $\mathrm{p}$ value. Additionally, we show that the presence of highlighted CYP $(19 A 1,1 B 1,2 F 1,7 A 1,17 A 1,2 D 6)$ in all probes on the microarray can enhance confidence to the result.

The limitation of this study is that only one type of skin cell was analyzed. It would be necessary to study keratinocytes and melanocytes in response to CsA, as it would give us a wide view of the entire skin tissue. On the other hand, this study can be advantageous, because the group is highly homogeneous. Moreover, it only affects a single view of the response to the drug and is less complicated.

An additional limitation is the lack of validation of highlighted genes for individual time to CsA exposition by using another method. However, each gene has already been mentioned or analyzed in other studies that were discussed previously. The presence of some of these genes has been proven in fibroblasts, but not all; therefore, our findings are the first covering the entire profile of CYP genes in human dermal fibroblasts.

Another limitation, but perhaps an advantage, is that the analysis of the microarrays concerns only the panel of $C Y P_{S}$, without genes connected or influencing their activity. Those genes are not analyzed, because they would not be significant to the results (single significant transcript between two or three, i.e., as for CYP2C19). For example, in the cases shown in Figure 2, the transcription factors: NFAT5 (nuclear factor of activated T-cells 5), NR2E3 (nuclear receptor 2 subfamily 2 group E member 3 , negatively regulating transcription) and FOXA2 (forkhead box a2, positively regulating transcription) that belong to neuron 2, hybridized with one out of the two probes present on the microarray. The same problem applies to KLF9 (Kruppel-like factor 9); namely two out of three transcripts had showed reverse regulation, despite FOXA2 being a 1B1,2F1, 7A1, 17A1 transcription factor and KLF regulating 
19A1. Their influence cannot be estimated based on the regulation of the highlighted CYP genes transcription or due to their own increase or decrease, under the influence of CsA. The distribution of 396 transcripts related to cytochrome P450 led us to select only one main pathway activated by CsA in skin fibroblasts, which was steroidogenesis. The main purpose of our work was to select the CYP genes, which plays a major role in response to CsA in human dermal fibroblasts, and this goal has been realized. Furthermore, we can conclude that the expression profile of cytochrome P450 in human dermal fibroblasts changes in response to CsA exposition in therapeutic concentration, especially affecting genes linked to steroid synthesis and/or metabolism. One of these pathways may be directly or indirectly responsible for the development of non-melanoma skin cancer in transplant recipients who have been using cyclosporin A for many years. Could steroids be the cause? Or is the reason an increased amount of free radicals formed during the induced reactions of steroid synthesis and/or metabolism? It may be both. To answer these questions, further studies are needed.

\section{Materials and Methods}

\subsection{Cell Culture}

Normal human dermal fibroblasts-adult (NHDF-Ad, CC-2511, CloneticsTM, Lonza, Basel, Switzerland) were cultured in sterile flasks of $25 \mathrm{~cm}^{2}$ surface with angled neck and antibacterial filters (Nunc ${ }^{\circledR}$; Sigma-Aldrich, Saint Louis, MO, USA) in initial cell density 3500 on $1 \mathrm{~cm}^{2}$. The cells were passaged on the sixth day and observed microscopically. To obtain a confluent monolayer, the cells were cultured in a basal fibroblast growth medium (CC-3131, FGM ${ }^{\mathrm{TM}}$, Lonza) and then in a medium with standard supplements, (CC-3132, Lonza) according to the obtained producer protocol. The cell cultures were maintained at $37^{\circ} \mathrm{C}$, enriched with $5 \% \mathrm{CO}_{2}$ of air atmosphere with constant humidity. Cells were counted microscopically in a haemocytometer.

\subsection{Cell Viability}

The cultured NHDF-Ad (CC-2511, Lonza, Basel, Switzerland) in confluent phase of growth and at a final number of $2 \times 10^{3}$ cells per 1 well were used for the test. The cells were seeded in 96-well plates to which CsA was added at a concentration range from 1.0 to 10,000 ng per $1 \mathrm{~mL}$ of the medium (Sandimmun, Novartis, Basel, Switzerland) and cultured for 8, 24, $48 \mathrm{~h}$ in standard conditions. Each procedure included a two blank sample with a fresh medium with and without cells. After incubation time the viability assay was performed using 3-(4,5-dimethyl-2-thiazol)-2,5-diphenyl-2H-tetrazolium bromide (MTT) according to the standard producer's protocol (M2128; Sigma-Aldrich). After $4 \mathrm{~h}$ of incubation with dye and liberation of the incorporated dye, absorbance was measured at $\lambda=570 \mathrm{~nm}$ and $\lambda=690 \mathrm{~nm}$ (reference wavelength) [38] using the MRX Revelation plate reader (Dynex Technologies, Chantilly, VA, USA). The viability test was repeated three times and there were eight replicates for each concentration of CSA.

\subsection{Cell Culture with CsA}

NHDFs (CC-2511, Lonza) were cultured in a liquid fibroblast growth medium (3132, Lonza) according to the protocol. After the confluent phase, CsA (Sandimmun, Novartis) was added to the medium at a selected concentration of $100 \mathrm{ng}$ per $1 \mathrm{~mL}$. The NHDFs were cultured for 8,24 and $48 \mathrm{~h}$ and after each time period, the total cells were rinsed three times and harvested, then used to isolate RNA.

\subsection{RNA Isolation}

After each time period total cell RNA was isolated with the use of TRIzol reagent in accordance with the producer's protocol (Invitrogen, Carlsbad, CA, USA). Isolated RNA was purified with RNeasy Mini Kit columns (Qiagen, Hilden, Germany). The purity of the RNA was evaluated spectrophotometrically and by using electrophoresis. 


\subsection{Microarray HGU-133A_2.0 Analysis}

Eight micrograms of pure RNA were obtained and were used for preparing one microarray. Analysis was performed by cDNA and cRNA synthesis; its fragmentation and hybridization were analyzed with HG-U133A_2.0 microarrays according to the Gene Expression Analysis Technical Manual (Affymetrix, Santa Clara, CA, USA). The fluorescence intensity signal was measured using GeneArray Scanner 3000 7G (Affymetrix). During all stages, the quality of cDNA and cRNA was controlled by performing agarose electrophoresis (1\%) and by absorbance measure in $\lambda$ 230/260/280 $\mathrm{nm}$ using spectrophotometric calculator GeneQuant II (Pharmacia Biotech, Uppsala, Sweden).

All data from performed microarrays are deposited in PL-Grid Infrastructure (www.plgrid.pl/en).

\subsection{Statistical Analysis}

The cell viability results were analyzed with descriptive statistics (mean and standard deviation) and analysis of variance (ANOVA) test (with statistical significance $p \leq 0.05$ ). The fluorescence signals of the 396 mRNAs obtained from cultured NHDFs with and without CsA were subjected to statistical analysis using STATISTICA 12 (StatSoft, Kraków, Poland), MATLAB 2011 (MathWorks, Natick, MA, USA) and GeneSpring 13.0 (Agilent Technologies, Inc., Santa Clara, CA, USA) software. Additionally, to achieve the goal of the study, we decided to use self-organizing maps of artificial neural networks to analyze the CYP's among the genes linked to cytochrome P450.

The data were grouped according to the time of culturing NHDFs without (0) and with CsA $(8,24,48 \mathrm{~h})$. The clusterization process and neural networks were made for groups of $396 \mathrm{mRNA}$ (Table S1) in which there were 91 CYPS (Table S2) and linked mRNAs that have a crucial impact on its functioning (Affymetrix NetAffx database, www.affymetrix.com). The mRNA fluorescence signals were normalized by the RMA (Robust Multichip Average; RMAExpress) method and then used in clusterization with Euclidean distance using the Ward method (STATISTICA 12) to analyze these 396 probe sets. Afterwards, the analyzed mRNA in all four groups $(0,8,24$ and $48 \mathrm{~h})$ were subjected to the creation of an artificial neural network. The neural network, by choice, was the self-organizing feature map (SOFM, or Kohonen map) [16], which was trained by unsupervised learning in STATISTICA 12. An analytical estimation of SOFM grouping quality was made using the Davies-Bouldin algorithm [17], which was calculated in MATLAB 2011 version.

The standard statistical analysis was performed in GeneSpring 13.0, where descriptive statistics were calculated for all 396 mRNA with 91 CYPs in each group $(0,8,24$ and $48 \mathrm{~h})$ and analyzed using ANOVA with the post hoc Tukey test. The significance level was set at $p \leq 0.05$. From statistically significant mRNAs $(p \leq 0.05)$ with a fold change parameter $(F C>1.2)$ greater than 1.2 had been distinguished.

\section{Conclusions}

On the basis of microarray analysis of the investigated NHDF cells, CsA induces the expression of CYP19A1, 1B1, 7A1, 2F1, 17A1 and inhibits the 2D6 gene, and it can be concluded that CsA changes the expression of CYP genes, which can take part in steroidogenesis. Increased expression of CYP genes related to steroid synthesis and/or metabolism under the influence of CsA shows the mechanism of its acting in human dermal fibroblast cells.

Supplementary Materials: The following are available online, Table S1: List of 396 ID mRNA and gene symbols used in the experiment; Table S2: List of 91 ID mRNA and gene symbols used in the experiment.

Author Contributions: Conceptualization, G.J.; Data curation, G.J. and T.J.; Formal analysis, G.J., T.J. and P.J.; Methodology, T.J., J.A. and G.J.; Project administration, G.J., U.M. and A.P.-P.; Supervision, G.J. and U.M.; Visualization, G.J.; Writing-original draft, G.J. and T.J.; Writing-review \& editing, G.J. and T.J.; all authors have read and approved the manuscript. 
Acknowledgments: This work was supported by KNW-1-013/K/7/0, KNW-1-019/K/6/0, KNW-1-024/N/5/0 and statutory research project of 2018 year of the Medical University of Silesia in Katowice. This research was supported in part by PL-Grid Infrastructure.

Conflicts of Interest: The authors declare that they have no conflicts of interest.

\section{References}

1. Colombo, D.; Ammirati, E. Cyclosporine in transplantation-A history of converging timelines. J. Biol. Regul. Homeost. Agents 2011, 25, 493-504. [PubMed]

2. Dehesa, L.; Abuchar, A.; Nuno-Gonzalez, A.; Vitiello, M.; Kerdel, F.A. The use of cyclosporine in dermatology. J. Drugs Dermatol. 2012, 11, 979-987. [PubMed]

3. Schultz, C. Safety and efficacy of cyclosporine in the treatment of chronic dry eye. Ophthalmol. Eye Dis. 2014, 6, 37-42. [CrossRef] [PubMed]

4. Amor, K.T.; Ryan, C.; Menter, A. The use of cyclosporine in dermatology: Part I. J. Am. Acad. Dermatol. 2010, 63, 925-928. [CrossRef] [PubMed]

5. Niwa, T.; Yamamoto, S.; Saito, M.; Shiraga, T.; Takagi, A. Effect of cyclosporine and tacrolimus on cytochrome p450 activities in human liver microsomes. Yakugaku Zasshi 2007, 127, 209-216. [CrossRef] [PubMed]

6. Nelson, D.R. The cytochrome p450 homepage. Hum. Genom. 2009, 4, 59-65.

7. Zanger, U.M.; Schwab, M.X. Cytochrome P450 enzymes in drug metabolism: Regulation of gene expression, enzyme activities, and impact of genetic variation. Pharmacol. Ther. 2009, 138, 103-141. [CrossRef] [PubMed]

8. Omura, T. Recollection of the early years of the research on cytochrome P450. Proc. Jpn. Acad. Ser. B Phys. 2011, 87, 617-640. [CrossRef] [PubMed]

9. Saeki, M.; Saito, Y.; Nagano, M.; Teshima, R.; Ozawa, S.; Sawada, J. mRNA expression of multiple cytochrome p450 isozymes in four types of cultured skin cells. Int. Arch. Allergy Immunol. 2002, 127, 333-336. [CrossRef] [PubMed]

10. Pelkonen, O.; Turpeinen, M.; Hakkola, J.; Honkakoski, P.; Hukkanen, J.; Raunio, H. Inhibition and induction of human cytochrome P450 enzymes: Current status. Arch. Toxicol. 2008, 82, 667-715. [CrossRef] [PubMed]

11. Oesch, F.; Fabian, E.; Guth, K.; Landsiedel, R. Xenobiotic-metabolizing enzymes in the skin of rat, mouse, pig, guinea pig, man, and in human skin models. Arch. Toxicol. 2014, 88, 2135-2190. [CrossRef] [PubMed]

12. Vickers, A.E.; Biggi, W.A.; Dannecker, R.; Fischer, V. Uptake and metabolism of cyclosporin A and SDZ IMM 125 in the human in vitro skin2 dermal and barrier function models. Life Sci. 1995, 57, 3215-3224. [CrossRef]

13. Tepeoğlu, M.; Ayva, S.;; Ok Atılgan, A.; Tunca, M.Z.; Özdemir, B.H.; Moray, G.; Yıldırım, S.; Arslan, G.; Haberal, M. Nonmelanoma skin cancer after kidney transplant. Exp. Clin. Transplant. 2014, 12, $233-237$. [PubMed]

14. Slominski, A.; Zbytek, B.; Nikolakis, G.; Manna, P.R.; Skobowiat, C.; Zmijewski, M.; Li, W.; Janjetovic, Z.; Postlethwaite, A.; Zouboulis, C.C.; et al. Steroidogenesis in the skin: Implications for local immune functions. J. Steroid Biochem. Mol. Biol. 2013, 137, 107-123. [CrossRef] [PubMed]

15. Slominski, A.T.; Zmijewski, M.A.; Semak, I.; Zbytek, B.; Pisarchik, A.; Li, W.; Zjawiony, J.; Tuckey, R.C. Cytochromes P450 and skin cancer: Role of local endocrine pathways. Anticancer Agents Med. Chem. 2014, 14, 77-96. [CrossRef] [PubMed]

16. Kohonen, T. Essentials of the self-organizing map. Neural Netw. 2013, 37, 52-65. [CrossRef] [PubMed]

17. Davies, D.L.; Bouldin, D.W. A cluster separation measure. IEEE Trans. Pattern Anal. Mach. Intell. 1979, 1, 224-227. [CrossRef] [PubMed]

18. Furlanut, M.; Baraldo, M.; Pea, F.; Marzocchi, V.; Croattino, L.; Galla, F. Blood concentrations and clinical effect of cyclosporin in psoriasis. Ther. Drug Monit. 1996, 18, 544-548. [CrossRef] [PubMed]

19. Heydendael, V.M.R.; Spuls, P.I.; Ten Berge, I.J.M.; Opmeer, B.C.; Bos, J.D.; de Rie, M.A. Cyclosporin trough levels: Is monitoring necessary during short-term treatment in psoriasis? A systematic review and clinical data on trough levels. Br. J. Dermatol. 2002, 147, 122-129. [CrossRef] [PubMed]

20. Umezawa, Y.; Ozawa, A. Optimal time for therapeutic drug monitoring of cyclosporine microemulsion in patients with psoriasis. Int. J. Dermatol. 2007, 46, 763-766. [CrossRef] [PubMed]

21. Cilião, H.L.; Ribeiro, D.L.; Camargo-Godoy, R.B.; Specian, A.F.; Serpeloni, J.M.; Cólus, I.M. Cytotoxic and genotoxic effects of high concentrations of the immunosuppressive drugs cyclosporine and tacrolimus in MRC-5 cells. Exp. Toxicol. Pathol. 2015, 67, 179-187. [CrossRef] [PubMed] 
22. Frušić-Zlotkin, M.; Soroka, Y.; Tivony, R.; Larush, L.; Verkhovsky, L.; Brégégère, F.M.; Neuman, R.; Magdassi, S.; Milner, Y. Penetration and biological effects of topically applied cyclosporin A nanoparticles in a human skin organ culture inflammatory model. Exp. Dermatol. 2012, 21, 938-943. [CrossRef] [PubMed]

23. Pereira, M.J.; Palming, J.; Rizell, M.; Aureliano, M.; Carvalho, E.; Svensson, M.K.; Eriksson, J.W. Cyclosporine A and tacrolimus reduce the amount of GLUT4 at the cell surface in human adipocytes: Increased endocytosis as a potential mechanism for the diabetogenic effects of immunosuppressive agents. J. Clin. Endocrinol. Metab. 2014, 99, E1885-E1894. [CrossRef] [PubMed]

24. Zheng, J.P.; Cheng, Z.; Jiang, J.; Ke, Y.; Liu, Z. Cyclosporin A upregulates ETB receptor in vascular smooth muscle via activation of mitogen-activating protein kinases and NF- KB pathways. Toxicol. Lett. 2015, 235, 1-7. [CrossRef] [PubMed]

25. Daheb, K.; Lipman, M.L.; Hildgen, P.; Roy, J.J. Artificial neural network modeling for drug dialyzability prediction. J. Pharm. Pharm. Sci. 2013, 16, 665-675. [CrossRef] [PubMed]

26. Chavez-Alvarez, R.; Chavoya, A.; Mendez-Vazquez, A. Discovery of possible gene relationships through the application of self-organizing maps to DNA microarray databases. PLoS ONE 2014, 9, e93233. [CrossRef] [PubMed]

27. Gajjar, K.; Martin-Hirsch, P.L.; Martin, F.L. CYP1B1 and hormone-induced cancer. Cancer Lett. 2012, 324, 13-30. [CrossRef] [PubMed]

28. Sugino, N. Molecular mechanisms of luteinization. Obstet. Gynecol. Sci. 2014, 57, 93-101. [CrossRef] [PubMed]

29. Chiang, T.S.; Yang, K.C.; Zheng, S.K.; Chiou, L.L.; Hsu, W.M.; Lin, F.H.; Huang, G.T.; Lee, H.S. The prediction of drug metabolism using scaffold-mediated enhancement of the induced cytochrome P450 activities in fibroblasts by hepatic transcriptional regulators. Biomaterials 2012, 33, 5187-5197. [CrossRef] [PubMed]

30. Inoue, T.; Miki, Y.; Abe, K.; Hatori, M.; Hosaka, M.; Kariya, Y.; Kakuo, S.; Fujimura, T.; Hachiya, A.; Honma, S.; et al. Sex steroid synthesis in human skin in situ: The roles of aromatase and steroidogenic acute regulatory protein in the homeostasis of human skin. Mol. Cell. Endocrinol. 2012, 362, 19-28. [CrossRef] [PubMed]

31. Shen, J.; Arnett, D.K.; Parnell, L.D.; Lai, C.-Q.; Straka, R.J.; Hopkins, P.N.; An, P.; Feitosa, M.F.; Ordovás, J.M. The effect of CYP7A1 polymorphisms on lipid responses to fenofibrate. J. Cardiovasc. Pharmacol. 2012, 59, 254-259. [CrossRef] [PubMed]

32. Yengi, L.G.; Xiang, Q.; Pan, J.; Scatina, J.; Kao, J.; Ball, S.E.; Fruncillo, R.; Ferron, G.; Roland Wolf, C. Quantitation of cytochrome P450 mRNA levels in human skin. Anal. Biochem. 2003, 316, 103-110. [CrossRef]

33. Smith, G.; Ibbotson, S.H.; Comrie, M.M.; Dawe, R.S.; Bryden, A.; Ferguson, J.; Wolf, C.R. Regulation of cutaneous drug-metabolizing enzymes and cytoprotective gene expression by topical drugs in human skin in vivo. Br. J. Dermatol. 2006, 155, 275-281. [CrossRef] [PubMed]

34. Korosec, T.; Acimovic, J.; Seliskar, M.; Kocjan, D.; Tacer, K.F.; Rozman, D.; Urleb, U. Novel cholesterol biosynthesis inhibitors targeting human lanosterol 14alpha-demethylase (CYP51). Bioorg. Med. Chem. 2008, 16, 209-221. [CrossRef] [PubMed]

35. Hu, T.; Khambatta, Z.S.; Hayden, P.J.; Bolmarcich, J.; Binder, R.L.; Robinson, M.K.; Carr, G.J.; Tiesman, J.P.; Jarrold, B.B.; Osborne, R.; et al. Xenobiotic metabolism gene expression in the EpiDermin vitro 3D human epidermis model compared to human skin. Toxicol. In Vitro 2010, 24, 1450-1463. [CrossRef] [PubMed]

36. Du, L.; Hoffman, S.M.G.; Keeney, D.S. Epidermal CYP2 family cytochromes P450. Toxicol. Appl. Pharmacol. 2004, 195, 278-287. [CrossRef] [PubMed]

37. Du, L.; Neis, M.M.; Ladd, P.A.; Keeney, D.S. Differentiation-specific factors modulate epidermal CYP1-4 gene expression in human skin in response to retinoic acid and classic aryl hydrocarbon receptor ligands. J. Pharmacol. Exp. Ther. 2006, 319, 1162-1171. [CrossRef] [PubMed]

38. Mosmann, T. Rapid colorimetric assay for cellular growth and survival: Application to proliferation and cytotoxicity assays. J. Immunol. Methods 1983, 65, 55-63. [CrossRef]

Sample Availability: Not available.

(C) 2018 by the authors. Licensee MDPI, Basel, Switzerland. This article is an open access article distributed under the terms and conditions of the Creative Commons Attribution (CC BY) license (http://creativecommons.org/licenses/by/4.0/). 